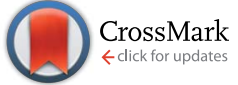

Cite this: RSC Adv., 2014, 4, 49588

Received 22nd August 2014

Accepted 29th September 2014

DOI: $10.1039 / \mathrm{c} 4 \mathrm{ra} 09057 \mathrm{~h}$

www.rsc.org/advances

\section{Enriched hydrogen production by bioconversion of biodiesel waste supplemented with ferric citrate and its nano-spray dried particles}

\author{
Saurabh Jyoti Sarma, ${ }^{a}$ Satinder Kaur Brar, ${ }^{\text {a }}$ Jérémy Reigner, ${ }^{\text {b }}$ Yann Le Bihan ${ }^{c}$ \\ and Gerardo Buelnac
}

\begin{abstract}
Increasing consumption of fossil fuels as well as the concern over pollution and global climate change has accelerated the development of the sustainable biofuel industry. Biodiesel, bioethanol and biomethane are already commercially available as alternatives of fossil fuels and the search for a more environmentally friendly biofuel, preferentially produced from non-food raw materials and capable of fulfilling the transportation energy requirement of the world for longer duration, is ongoing. In this context, biohydrogen produced from waste biomass is an ideal option. It has higher energy content compared to fossil and biofuels of equivalent mass and produces water as the only major emission during combustion. In the present investigation, crude glycerol (CG) generated as by-product of the biodiesel production process has been used as feedstock for biohydrogen production and different supplements have been evaluated for increasing the product yield. Nano-spray dried ferric citrate particles have been found to enhance the hydrogen production by $50.45 \%$. Hydrogen production using extremely low CG concentration of $100 \mathrm{mg} \mathrm{L}^{-1}$ has been found to produce $22.7 \mathrm{~mol}-\mathrm{H}_{2}$ per kg CG; which is 2.75-fold higher than $8.25 \mathrm{~mol}-\mathrm{H}_{2}$ per kg CG, known for dark fermentation.
\end{abstract}

\section{Introduction}

Considering global energy security as well as greenhouse gas emission reduction potential, increased production and application of biofuels is inevitable. At this juncture, biofuel production is not equally profitable in all countries and hence, different governments have applied encouraging policies, such as tax exemption. ${ }^{1}$ Moreover, in order to ensure increased biofuel consumption and replacement of fossil fuel, mandatory blending of fossil fuels with $2-10 \%$ of biofuel has been targeted in many countries. ${ }^{1}$ There are different types of biofuels presently in use; however, greenhouse gas emission reduction potential, availability of raw materials and energy content of these biofuels are not similar. Therefore, for long term production and use, all of them may not be equally suitable. ${ }^{2}$ In this context, biohydrogen could be considered as an emerging biofuel with very high sustainability. It can be produced from a diverse group of renewable raw materials and hence, does not necessarily compete with food crop based biomass for feedstock. Additionally, during combustion, hydrogen is converted

${ }^{a}$ Institut National de la Recherche Scientifique (INRS), Centre Eau, Terre \& Environnement, 490, Rue de la Couronne, Québec (QC), G1K 9A9, Canada. E-mail: satinder.brar@ete.inrs.ca; Fax: +1 418654 2600; Tel: +1 4186543116

${ }^{b}$ Université Paris-Est Créteil Val de Marne, 61 avenue du Général de Gaulle, 94010 Créteil Cedex, France

${ }^{c}$ Centre de Recherche Industrielle du Québec (CRIQ), Québec (QC), G1P 4C7, Canada to water and does not produce any carbon based emission. ${ }^{2-4}$ Energy content of hydrogen is $142 \mathrm{~kJ} \mathrm{~g}^{-1}$, which is higher than any fossil fuel of equivalent mass., ${ }^{2,4}$ Thus, hydrogen production by bioconversion of low cost agro-industrial organic waste materials has commercial importance. In the present study, enhanced hydrogen production by bioconversion of crude glycerol has been investigated. In the course of biodiesel production by trans-esterification of vegetable oil, animal fat or any other lipid based feedstock; crude glycerol (CG) is produced as a by-product. By weight, the amount of glycerol generated by the process could be as high as $10 \%$ of the biodiesel produced. ${ }^{5}$ Corresponding to increased global biodiesel production, crude glycerol production is also increasing and consequently, CG price has decreased to around \$ 0.05 per pounds. ${ }^{5}$ Thus, application of CG as a feedstock for hydrogen production by anaerobic fermentation could be considered as a lucrative option for its value-addition.

NiFe-hydrogenase and FeFe-hydrogenase are two crucial enzymes responsible for microbial hydrogen production in anaerobic environment. ${ }^{6-9}$ The active site of NiFe-hydrogenase has one $\mathrm{Ni}$ and one $\mathrm{Fe}$ atom; whereas, two $\mathrm{Fe}$ atoms are present in the active site of FeFe-hydrogenase. ${ }^{\mathbf{1 0}, \mathbf{1 1}}$ Therefore, hydrogen production media should contain sufficient amount of $\mathrm{Ni}$ and $\mathrm{Fe}$, so that synthesis of these enzymes are not affected. In CG, only a negligible amount of Ni may be present; whereas, the amount of Fe presents in CG could be as low as 31.6 \pm 19.0 $\mathrm{mg} \mathrm{kg}{ }^{-1}$ to $44.41 \pm 16 \mathrm{mg} \mathrm{kg}{ }^{-1} \cdot{ }^{12}$ For hydrogen production by 
crude glycerol bioconversion, the feedstock needs to be diluted to an optimum concentration; which is usually around $10 \mathrm{~g} \mathrm{~L}^{-1}{ }^{\mathbf{1 2}}$ Hence, final concentration of $\mathrm{Fe}$ in a biohydrogen production medium prepared using only CG $\left(10 \mathrm{~g} \mathrm{~L}^{-1}\right)$ will be as low as 0.31 to $0.44 \mathrm{mg} \mathrm{L}^{-1}$. In this context, CG supplemented with $\mathrm{Ni}$ and $\mathrm{Fe}$ might have beneficial effect on biohydrogen production by CG bioconversion. Therefore, the purpose of the present study was to evaluate the effect of ferric citrate, ferrous sulfate, nickel acetate, and nickel chloride supplements on hydrogen production by CG bioconversion. Owing to their very large specific surface area, nanoparticles are generally considered to have higher reactivity. ${ }^{13}$ Therefore, aforementioned supplements were used in nanospray dried form. For the present investigation, Enterobacter aerogenes, a well-known hydrogen producing microorganism has been used. ${ }^{\mathbf{1 4 1 5}}$ CG used in this investigation was supplied by Rothsay® (Canada) and its detailed characterization could be found in Sarma et al. (2013)..$^{12}$

\section{Experimental}

\section{Microorganism and inoculum preparation}

Enterobacter aerogenes NRRL B-407, a rod-shaped, gramnegative, facultative anaerobic bacterium from Enterobacteriaceae family has been used for hydrogen production experiments. It was collected from ARS, USDA, USA in freezedried form. To subculture the organism and to prepare inoculum for the study, a synthetic medium composed of glucose and casein peptone ( $5 \mathrm{~g} \mathrm{~L}^{-1}$ each); $\mathrm{KH}_{2} \mathrm{PO}_{4}\left(2 \mathrm{~g} \mathrm{~L}^{-1}\right)$; and yeast extract and $\mathrm{MgSO}_{4} \cdot 7 \mathrm{H}_{2} \mathrm{O}\left(0.5 \mathrm{~g} \mathrm{~L}^{-1}\right.$ each) was used. Serum bottles of $125 \mathrm{~mL}$ with $50 \mathrm{~mL}$ of working volume were used to culture the microorganism. Media taken in these bottles were first sparged with $\mathrm{N}_{2}$ gas for $2 \mathrm{~min}$; the bottles were immediately closed with aluminum crimp seals having silicon septa and sterilized by autoclaving. After inoculation, the culture bottles were incubated in an incubator shaker operated at $30{ }^{\circ} \mathrm{C}$ and $150 \mathrm{rpm}$ and $5 \%(\mathrm{v} / \mathrm{v})$ of microbial culture at its exponential phase of growth was used as an inoculum for hydrogen production.

\section{Preparation and characterization of different nano-spray dried particles}

Ferric citrate, ferrous sulfate, nickel acetate, and nickel chloride particles used in the present investigation have been prepared by using a nano-spray dryer (Buchi B-90, Switzerland). For the preparation of ferrous sulfate, nickel acetate, and nickel chloride particles, a solution of $50 \mathrm{~g} \mathrm{~L}^{-1}$ of each compound was separately prepared in distilled water and subjected to nanospray drying process. For all particles, the respective solution was fed to the nano-spray dryer at a flow rate of nearly $20 \mathrm{~mL} \mathrm{~h}^{-1}$ (flow level 3). Similarly, in each case, the maximum temperature of the spray dryer was kept constant at $120{ }^{\circ} \mathrm{C}$ and the air flow rate was maintained at $120 \mathrm{~L} \mathrm{~min}^{-1}$. The spray cap used for entire spray drying process was of $4.0 \mu \mathrm{m}$ mesh size. During the process, particles were accumulated on the internal surface of the collecting electrode which was subsequently recovered by particle collecting accessories supplied with the instrument. Collected nano-spray dried particles were used in hydrogen production experiments. For preserving the particles, airtight glass vials were used. For the preparation of ferric citrate particles, almost similar process was applied. However, as ferric citrate solution could not be prepared using water in room temperature; either hot water or $1 \mathrm{~N} \mathrm{NaOH}$ was used.

Zeta potential distribution of nano-spray dried ferric citrate particles prepared using hot water was determined by a zetasizer nano ZS system (Malvern instruments Ltd., UK). For this purpose, small amount of the particles was dispersed in Milli-Q water and $1 \mathrm{~mL}$ of this solution was analyzed.

A scanning electron microscope (Zeiss EVO® 50 Smart SEM) has been used for morphological characterization of the nanospray dried particles prepared for this investigation. The ferric citrate nano-spray dried particles were first dispersed in Milli-Q water; a small amount of dispersed nano-spray dried particles was taken on a piece of aluminum foil, air dried and finally transferred to SEM stub. Prior to SEM analysis, samples were coated with gold by using a sputter coater.

\section{Screening of different nano-spray dried particles for biohydrogen production}

Purpose of this investigation was to investigate the effect of nano-spray dried particles prepared using ferric citrate, ferrous sulfate, nickel acetate, and nickel chloride, on hydrogen production by CG bioconversion. All the particle types were prepared using aqueous solution as already mentioned in previous section. CG stock solution was distributed in different $125 \mathrm{~mL}$ serum bottles in such a way that after inoculating with $5 \%(\mathrm{v} / \mathrm{v})$ inoculum, total volume of the medium and concentration of CG in each bottle would become $25 \mathrm{~mL}$ and $12 \mathrm{~g} \mathrm{~L}^{-1}$, respectively. About $50 \mathrm{mg} \mathrm{\textrm {L } ^ { - 1 }}$ of each nano-spray dried particle type was separately added to different bottles and the medium $\mathrm{pH}$ of each bottle was adjusted to 6 . After bubbling the media with nitrogen gas, the bottles were sealed, sterilized, inoculated, and incubated in the same manner as described for inoculum preparation. One $\mathrm{mL}$ of biogas containing hydrogen was collected from the headspace of each bottle using a $5 \mathrm{~mL}$ gastight glass syringe (SEG, Australia) and stored in $5.9 \mathrm{~mL}$ airtight glass vials (Exetainer®, Labco, UK). Prior to storing the gas samples, glass vials were flashed with ultrapure nitrogen gas and evacuated using a needle fitted vacuum pump.

\section{Investigation of the effect of Fe-citrate particle preparation method on hydrogen production}

As already mentioned, two different types of ferric citrate particles were prepared either by dissolving it in hot water or in $\mathrm{NaOH}(1 \mathrm{~N})$. About 10, 50, 100, 300 and $500 \mathrm{mg} \mathrm{L}^{-1}$ of both particles were separately added to different serum bottles containing $12 \mathrm{~g} \mathrm{~L}^{-1} \mathrm{CG}$ and their effect on hydrogen production was investigated by similar method mentioned in previous section. 
Investigation of the effect of CG concentration on $\mathrm{H}_{2}$ production using media supplemented with ferric citrate particles

The purpose of this study was to investigate the effect of ferric citrate nano-spray dried particles on hydrogen production by using different concentrations of CG. From previous investigation, $100 \mathrm{mg} \mathrm{\textrm {L } ^ { - 1 }}$ of ferric citrate particles was selected for this investigation. Media were prepared by using $100 \mathrm{mg} \mathrm{L}^{-1}, 500 \mathrm{mg} \mathrm{L}^{-1}$, $1000 \mathrm{mg} \mathrm{L}^{-1}, 2000 \mathrm{mg} \mathrm{L}^{-1}, 5000 \mathrm{mg} \mathrm{L}^{-1}$ and, $10000 \mathrm{mg} \mathrm{L}^{-1}$ of CG, and $100 \mathrm{mg} \mathrm{L}{ }^{-1}$ of ferric citrate particles were added to each medium. Similar to different hydrogen production experiments already discussed, serum bottles containing these media were processed, inoculated, incubated, and gas samples were collected, stored and analyzed.

\section{Hydrogen analysis}

Gas samples stored in $5.9 \mathrm{~mL}$ airtight glass vials were analyzed by gas chromatography. The GC system used for this purpose was of Varian 3800 model (USA), equipped with automatic sample injector. The detector was a thermal conductivity detector (TCD) and the column used was PoraPLOT Q ${ }^{\circledR}$ (Agilent technology, USA). For this analysis, $\mathrm{N}_{2}$ was used as the carrier gas and column temperature was kept constant at $100{ }^{\circ} \mathrm{C}$. The carrier gas flow rate of $3.5 \mathrm{~mL} \mathrm{~min}^{-1}$ was used and the retention time for hydrogen was determined to be $4.5 \mathrm{~min}$.

\section{Results and discussion}

\section{Characterization of nano-spray dried particles}

SEM images of the ferric citrate particles used in the present investigation have been presented in Fig. 1. A very broad particle size distribution has been observed with the diameters ranging from around $1.73 \mu \mathrm{m}$ to $468 \mathrm{~nm}$ or smaller. Particles were completely spherical and an aggregation tendency was observed among them. Zeta potential distribution of these particles has been presented in Fig. 2. From Fig. 2, the zeta potential was determined to be more than $\pm 5 \mathrm{mV}$, which ruled out the possibility of instant coagulation of the particles. However, it was lesser than $\pm 40 \mathrm{mV}$, which implied that aggregation among the particles was possible. Therefore, the observed aggregation behavior of ferric citrate particles can be considered as normal. By proper surface modification or by applying a stabilizer, aggregation of the particles could be controlled. As aggregation behavior of the particles may control their functional properties, as a separate study, the effect of ferric citrate particles' aggregation on hydrogen production can be investigated.

\section{Screening of different nano-spray dried particles for biohydrogen production}

In Fig. 3 cumulative hydrogen production by bioconversion of CG supplemented with different nano-spray dried particles has been presented. In general, nickel based particles were found to be inhibitory for hydrogen production. As there are different probable mechanisms for nickel toxicity in microorganisms; nickel particles may be toxic to the bacterium used in this investigation. ${ }^{\mathbf{1 6}}$ It could be a reason for reduced hydrogen production in the case of nickel acetate, and nickel chloride. Compared to nickel containing particles, more hydrogen production has been observed in the case of iron containing particles. Between iron containing particles, particles made up of ferric citrate were found to produce more amount (nearly 2.5 folds more) of hydrogen (Fig. 3) than ferrous sulfate particles. Citrate moiety of ferric citrate containing 6 carbon and 5 hydrogen atoms might have served as an additional/easily accessible substrate for the process and it could be a reason for improved hydrogen production. During fermentation some bacteria can use Fe(III) as electron acceptor; ${ }^{17}$ thus ferric citrate might have additional beneficial role for the process. Based on this observation, ferric citrate particles have been selected for further investigation.

\section{Effect of Fe-citrate particle preparation method on hydrogen production}

The purpose of the present investigation was to compare the effect of hot water based and $\mathrm{NaOH}$ based nano-spray dried ferric citrate particles on hydrogen production. Different

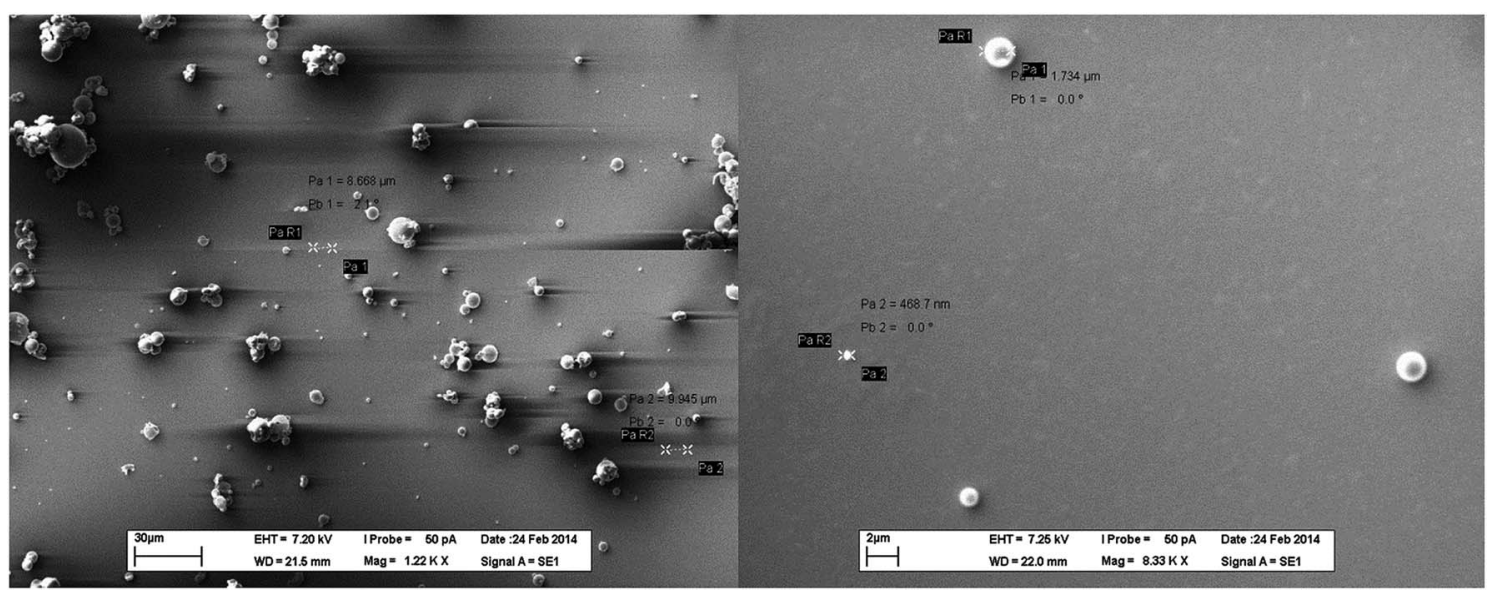

Fig. 1 SEM images (at different magnification) of ferric citrate particles prepared using hot water. 
Zeta Potential Distribution

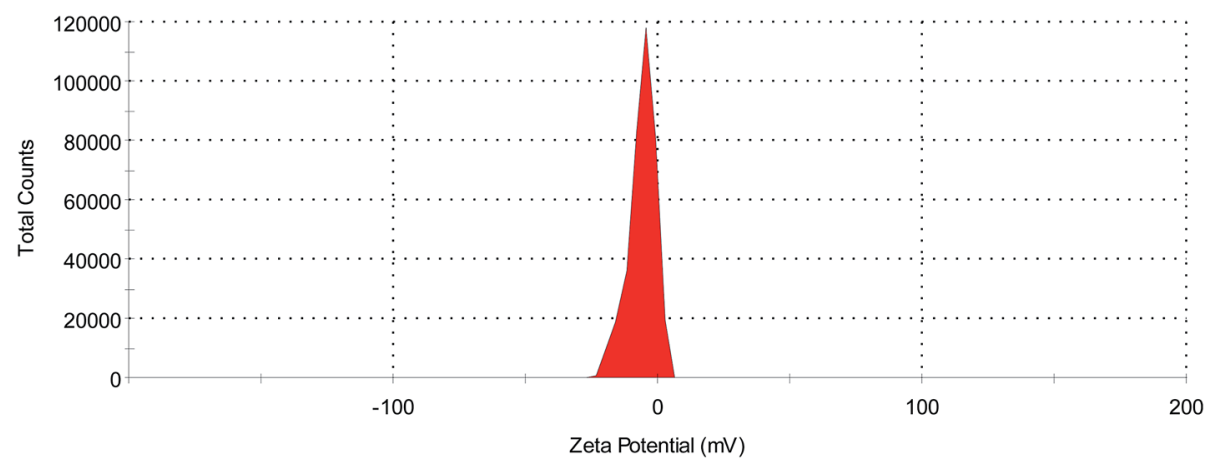

Fig. 2 Zeta potential distribution of ferric citrate particles prepared using hot water.

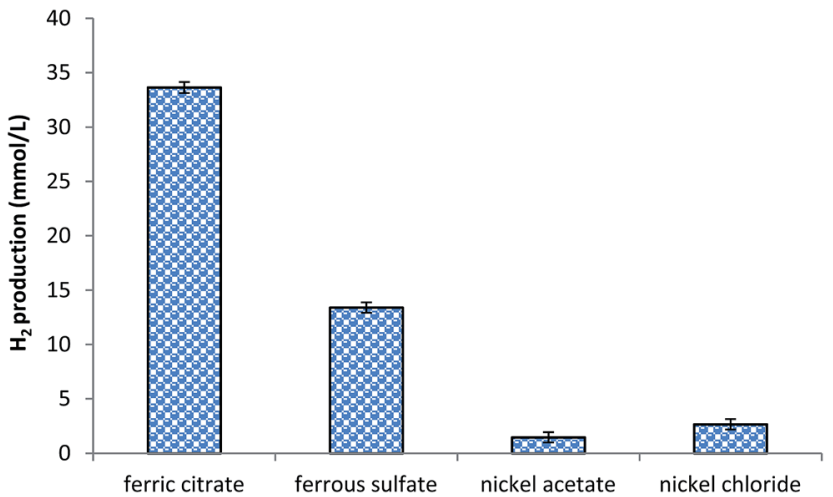

Fig. 3 Cumulative hydrogen production obtained after $48 \mathrm{~h}$ of incubation. $50 \mathrm{mg} \mathrm{L}^{-1}$ of respective nano-spray dried particles were added to $12 \mathrm{~g} \mathrm{~L}^{-1}$ of $C G$.

amounts of these particles, ranging from $10 \mathrm{mg} \mathrm{L}^{-1}$ to $500 \mathrm{mg} \mathrm{L}^{-1}$ were tested as supplement for hydrogen production by CG bioconversion and the results have been presented in Fig. 4. From Fig. 4, it is clear that compared to ferric citrate particles prepared using $\mathrm{NaOH}$, hot water based particles are more favorable as a supplement for hydrogen production. As

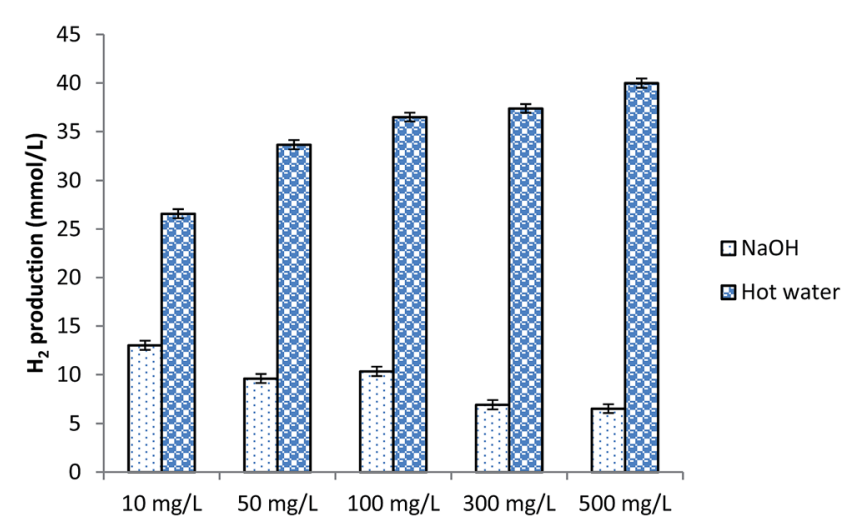

Fig. 4 Cumulative hydrogen production obtained after $48 \mathrm{~h}$ of incubation. Different concentrations of two different types of ferric citrate particles were added to $12 \mathrm{~g} \mathrm{~L}^{-1}$ of CG. shown in Fig. 4, corresponding to increased concentration of $\mathrm{NaOH}$ based ferric citrate from $10 \mathrm{mg} \mathrm{L}^{-1}$ to $500 \mathrm{mg} \mathrm{L}^{-1}$, decreased hydrogen production has been observed. In addition to ferric citrate, $\mathrm{NaOH}$ based particles may also contain $\mathrm{Na}^{+}$ions in large number. Therefore, unfavorable ionic strength of the medium supplemented with such particle could be one reason of observed reduced hydrogen production. On the contrary, by increasing the concentration of hot water based ferric citrate particles from $10 \mathrm{mg} \mathrm{L}^{-1}$ to $500 \mathrm{mg} \mathrm{L}^{-1}$, hydrogen production was increased by nearly $50.45 \%$ (Fig. 4). Based on this observation, $100 \mathrm{mg} \mathrm{L}^{-1}$ of hot water based ferric citrate particles have been selected for further investigation. If relatively higher concentration of the supplement (ferric citrate particles) is used, medium $\mathrm{pH}$ will decrease and presence of higher concentration of the particles might have negative effect on the microorganisms used for hydrogen production. Thus, choosing a relatively lower concentration of the particles will be an appropriate option.

\section{Effect of CG concentration on $\mathrm{H}_{2}$ production using media supplemented with nano-spray dried ferric citrate particles}

The purpose of this experiment was to determine the effect of initial CG concentration on hot water based ferric citrate particle supplemented hydrogen production process. Results of this investigation have been presented in Fig. 5 and from the figure it can be inferred that at constant ferric citrate particle concentration (100 $\mathrm{mg} \mathrm{L}^{-1}$ ), by increasing the initial CG concentration from $100 \mathrm{mg} \mathrm{L^{-1 }}$ to $10 \mathrm{~g} \mathrm{~L} \mathrm{~L}^{-1}$, cumulative hydrogen production can be increased by nearly 12 folds. It is quite obvious as optimum CG concentration for a batch hydrogen production process has been found to be around $10 \mathrm{~g} \mathrm{~L}^{-1} \cdot \mathbf{1 2}^{2}$

As shown in Fig. 5, however, if total hydrogen production by bioconversion of $1 \mathrm{~kg}$ of CG is considered; the amount projected to be produced at initial CG concentration of $100 \mathrm{mg} \mathrm{L}^{-1}$ was found to be nearly 8.20 folds more than that of $10 \mathrm{~g} \mathrm{~L}^{-1}$. In the case of $100 \mathrm{mg} \mathrm{L}^{-1} \mathrm{CG}$, the amount of ferric citrate particles (100 $\mathrm{mg} \mathrm{L}^{-1}$ ) added to the process was equal to that of substrate (CG). Therefore, for hydrogen production media prepared using one $\mathrm{kg}$ of $\mathrm{CG}$, nearly $1 \mathrm{~kg}$ of ferric citrate particles would be 


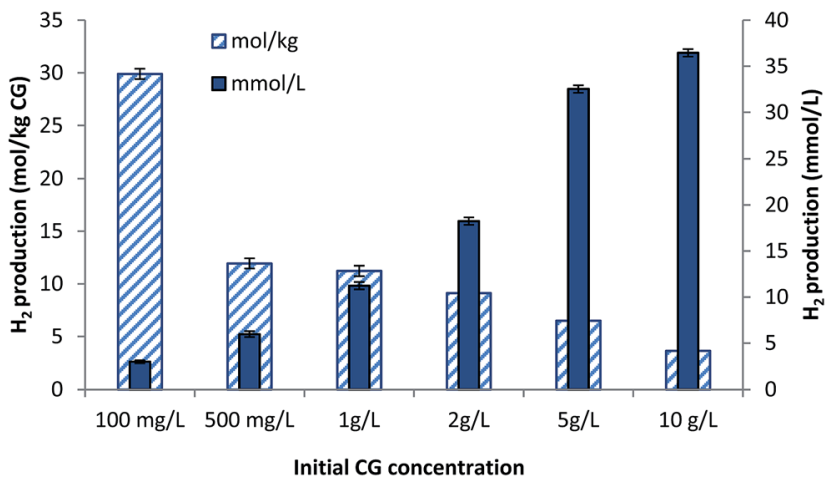

Fig. 5 Cumulative hydrogen production obtained after $48 \mathrm{~h}$ of incubation. $100 \mathrm{mg} \mathrm{L}^{-1}$ of ferric citrated particles (prepared with hot water) were added to different concentrations of CG. Projected hydrogen yields by bioconversion of $1 \mathrm{~kg}$ of CG have also been shown for each initial CG concentration.

needed. However, if an initial CG concentration of $10 \mathrm{~g} \mathrm{~L}^{-1}$ is used and $100 \mathrm{mg} \mathrm{L}^{-1}$ of the particles is added as supplement; for $1 \mathrm{~kg}$ of CG, only $10 \mathrm{~g}$ of the particles would be required. Therefore, 8.20 folds increase in hydrogen production projected

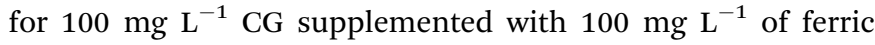
citrate particles could be attributed to the additional amount of the particles required for the approach.

In Fig. 6, cumulative hydrogen productions by only CG (100 mg L $\left.{ }^{-1}\right)$; CG (100 $\mathrm{mg} \mathrm{L}^{-1}$ ) supplemented with ferric citrate $\left(100 \mathrm{mg} \mathrm{L}^{-1}\right)$ as well as CG $\left(100 \mathrm{mg} \mathrm{L}^{-1}\right)$ supplemented with nano-spray dried ferric citrate particles $\left(100 \mathrm{mg} \mathrm{L}^{-1}\right)$ have been presented. Fig. 6 demonstrates that by supplementing the CG bioconversion process with ferric citrate or its nano-spray dried particles, $17.18 \%$ to $31.71 \%$ percent improvement in hydrogen production can be achieved. However, supplementation process will involve additional process cost; hence, a proper cost benefit analysis of the approach is a prerequisite for its industrial trial. Moreover, it should also be determined, whether the application of ferric citrate or its nano-spray dried particle will be appropriate for large scale hydrogen production using CG. Likewise, process mode and hydrogen partial pressure in the headspace of the reactor are known to have influence on

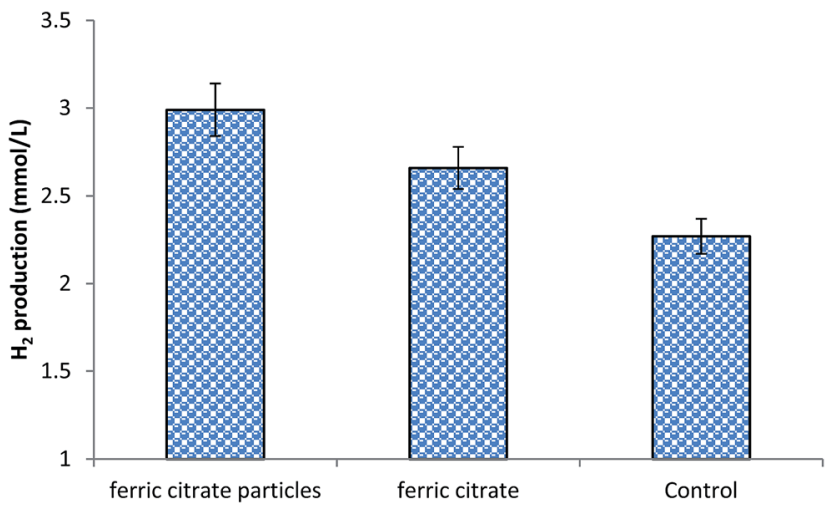

Fig. 6 Cumulative hydrogen production obtained after 48 h of incubation. Control is only CG $\left(100 \mathrm{mg} \mathrm{L}^{-1}\right)$. cumulative hydrogen production. Thus, in order to determine the potential of the approach, unlike the closed batch process used in the present investigation, hydrogen production using CG supplemented with ferric citrate or its nano-spray dried particle should also be evaluated using process with proper $\mathrm{pH}$ control and at relatively low hydrogen partial pressure.

A summary of different reports on hydrogen production by microbial conversion of crude glycerol have been presented in Table 1. From the table, it has been observed that compared to dark-fermentation, higher hydrogen yield has been reported for photo-fermentation. It is well known that during darkfermentation different byproducts (acetic acid, butyric acid etc.) are formed; which is not the case for photo-fermentation. Theoretically, therefore, photo-fermentation has higher hydrogen yield, and present observation is an example. However, dark-fermentation is the mostly studied method of biohydrogen production because; it has many technical advantages over photo-fermentation and other processes. Firstly, hydrogen production rate of dark-fermentation is higher than photo-fermentation. ${ }^{24}$ It implies that compared to darkfermentation, photo-fermentation is a slower process. Secondly, poor light conversion efficiency, high energy requirement by the enzyme (nitrogenase) and the high cost involved in construction and maintenance of bioreactors suitable for photo-fermentation are some other disadvantages of photo-fermentation. ${ }^{25}$ Thirdly, dark-fermentation will be easy to scale up since; a simple conventional anaerobic digester could be used for this purpose. Additionally, if waste biomass based highly turbid feedstock is subjected to photo-fermentation, light penetration into the medium may be difficult. Thus, in spite of relatively lower theoretical hydrogen yield, darkfermentation is mostly chosen for this purpose.

From the table, it is evident that compared to reported maximum hydrogen yield by dark fermentation of CG $(8.25 \mathrm{~mol}-$ $\mathrm{H}_{2}$ per $\mathrm{kg}$ CG); by using an initial CG concentration of $100 \mathrm{mg} \mathrm{L}{ }^{-1}$ with no supplementary nutrient, 2.75 folds more hydrogen (22.7 mol- $_{2}$ per $\mathrm{kg}$ CG) could be produced. This observation indicated that hydrogen production by using an initial substrate concentration as low as $100 \mathrm{mg} \mathrm{L}^{-1}$ can significantly improve cumulative hydrogen production by maximum feedstock utilization. This approach may enhance hydrogen yield not only in the case of CG bioconversion but also for any other substrate. Three possible reasons for this observed improved hydrogen yield are discussed below. (i) Volatile fatty acids (VFAs), such as acetate, butyrate etc., are produced as byproducts of fermentative hydrogen production. ${ }^{26}$ Production of these byproducts can quickly decrease the $\mathrm{pH}$ of the medium to trigger a metabolic shift, which may lead to decreased cumulative hydrogen production. ${ }^{27}$ At low initial substrate concentration $\left(100 \mathrm{mg} \mathrm{L}^{-1}\right)$, lesser amount of these VFAs will be produced; hence, the concentration of these compounds in the medium will be lower than a process with high initial substrate concentration. Thus, inhibitory effect of VFAs could be avoided if a relatively low initial substrate concentration is used. This, approach has industrial significance as it may reduce the requirement of large amount of alkali and acid for process $\mathrm{pH}$ control. (ii) Hydrogen partial pressure buildup in the headspace 


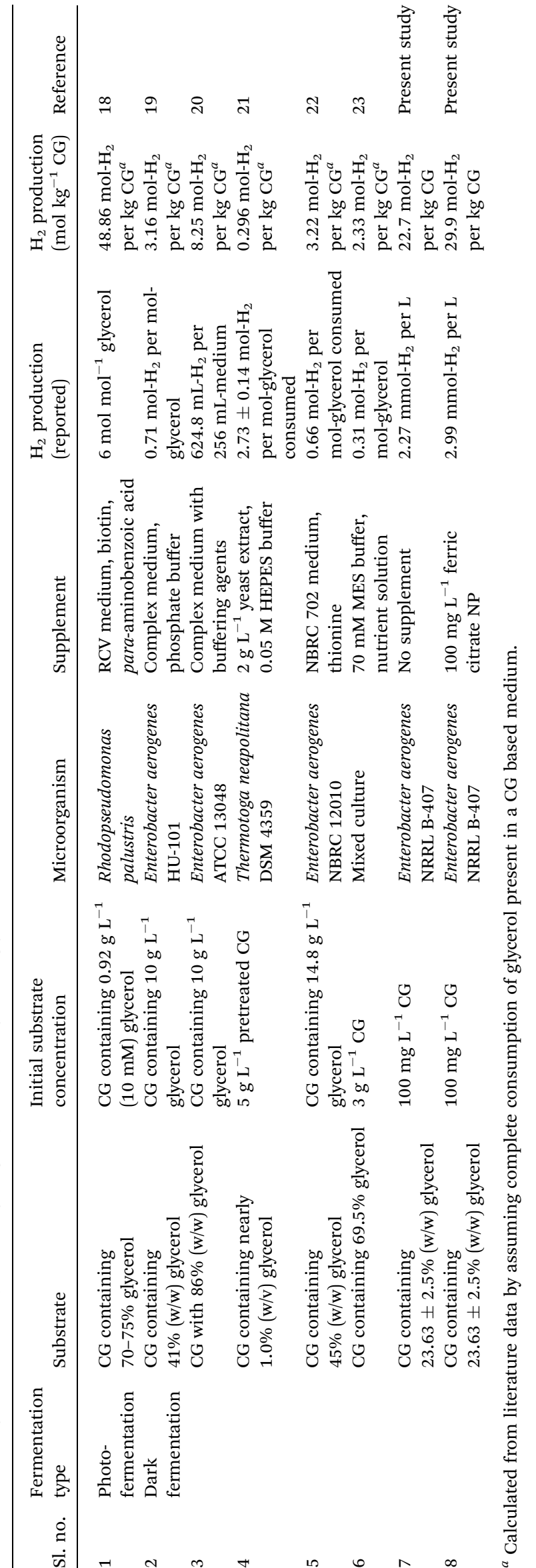

of the reactor can reduce cumulative hydrogen production and by periodically flushing out the accumulated gas, hydrogen production can be increased..$^{21}$ If an initial substrate concentration as low as $100 \mathrm{mg} \mathrm{L}^{-1}$ is used, only a small amount of hydrogen will be produced per liter of medium; therefore, hydrogen accumulation in the headspace will be far lower than a process with high initial substrate concentration such as, $10 \mathrm{~g} \mathrm{~L}^{-1}$. Thus, low partial pressure of hydrogen in the headspace could be one of the reasons of improved hydrogen yield per kg of substrate observed in the present investigation. (iii) In the case of present investigation, initial CG concentrations ranging from $100 \mathrm{mg} \mathrm{L}^{-1}$ to $10 \mathrm{~g} \mathrm{~L}^{-1}$ were used; however, inoculum size was kept constant at $5 \%(\mathrm{v} / \mathrm{v})$. Therefore, in the case of the process with $100 \mathrm{mg} \mathrm{L}^{-1}$ of CG, the amount of active microbial biomass introduced per $\mathrm{kg}$ of substrate (CG) was 100 times more than that of the process with $10 \mathrm{~g} \mathrm{~L}^{-1} \mathrm{CG}$. Thus, the role of excess amount of biomass is undeniable.

\section{Conclusions}

Among nano-spray dried ferric citrate, ferrous sulfate, nickel chloride and nickel acetate nano-spray dried particles, only ferric citrate particles were found to have beneficial effect on hydrogen production. Two different types of ferric citrate particles were prepared, either by dissolving it in hot water or in $\mathrm{NaOH}$ solution. Between these two particles, hot water based ones were found to enhance the hydrogen production by $50.45 \%$. Apart from supplementation, initial substrate concentration has been identified as a crucial factor to determine the hydrogen yield. At extremely low initial CG concentration of $100 \mathrm{mg} \mathrm{L}^{-1}$, by supplementing the process with ferric citrate particles, a hydrogen yield as high as 29.9 mol- $\mathrm{H}_{2}$ per $\mathrm{kg}$ CG has been achieved. This yield is significantly higher than the value of 8.25 mol- $\mathrm{H}_{2}$ per $\mathrm{kg}$ CG; previously known for dark fermentative hydrogen production.

\section{Acknowledgements}

CRIQ, NSERC, MRI (Quebec-Parana and Quebec-Vietnam) and INRS-ETE Canada have been acknowledged for financial support. The authors are also thankful to "merit scholarship program for foreign students (FQRNT)" for financial assistance to Mr Saurabh Jyoti Sarma.

\section{References}

1 M. Banse, A. Rothe, A. Tabeau, H. van Meijl and G. Woltjer, Food security and development policy, factor markets working papers, 2013, p. 19.

2 J. X. W. Hay, T. Y. Wu, J. C. Juan and M. J. Jahim, Biofuels, Bioprod. Biorefin., 2013, 7, 334-352.

3 N. H. Mohd Yasin, M. Fukuzaki, T. Maeda, T. Miyazaki, C. M. H. C. Maail, H. Ariffin and T. K. Wood, Int. J. Hydrogen Energy, 2013, 38, 10277-10283.

4 E. B. Sydney, C. Larroche, A. C. Novak, R. Nouaille, S. J. Sarma, S. K. Brar, L. A. J. Letti, V. T. Soccol and C. R. Soccol, Bioresour. Technol., 2014, 159, 380-386. 
5 F. Yang, M. A. Hanna and R. Sun, Biotechnol. Biofuels, 2012, 5, 13.

6 O. Schmidt, P. K. Wüst, S. Hellmuth, K. Borst, M. A. Horn and H. L. Drake, Appl. Environ. Microbiol., 2011, 77, 58425850.

7 J. Y. Kim, B. H. Jo and H. J. Cha, Microb. Cell Fact., 2010, 9, 54. 8 Y. Montet, E. Garcin, A. Volbeda, C. Hatchikians, M. Frey and J. C. Fontecilla-Camps, Pure Appl. Chem., 1998, 70(1), 25-31. 9 S. Y. Xu, P. Q. He, S. Z. Dewi, X. L. Zhang, C. Ekowati, T. J. Liu and X. H. Huang, Curr. Microbiol., 2013, 66, 499-506.

10 A. Volbeda, E. Garcin, C. Piras, A. L. de Lacey, V. M. Fernandez, E. C. Hatchikian, M. Frey and J. C. Fontecilla-Camps, J. Am. Chem. Soc., 1996, 118, 1298912996.

11 S. J. Sarma, G. S. Dhillon, S. K. Brar, Y. L. Bihan and G. Buelna, in Enzymes in value-addition of waste, ed. S. K. Brar and M. Verma, Nova Publishers, 2014, pp. 173-192.

12 S. J. Sarma, S. K. Brar, Y. Le Bihan, G. Buelna and C. R. Soccol, J. Chem. Technol. Biotechnol., 2013, 88, 22642271.

13 H. P. Van Leeuwen, J. Buffle, J. F. Duval and R. M. Town, Langmuir, 2013, 29, 10297-10302.

14 S. Tanisho, in Biohydrogen, ed. O. R. Zaborsky, J. R. Benemann, T. Matsunaga, J. Miyake and A. S. Pietro, Springer, 1998, pp. 273-279.
15 C. Zhang, F. X. Lv and X. H. Xing, Bioresour. Technol., 2011, 102, 8344-8349.

16 L. Macomber and R. P. Hausinger, Metallomics, 2011, 3, 1153-1162.

17 C. A. Pham, S. J. Jung, N. T. Phung, J. Lee, I. S. Chang, B. H. Kim, H. Yi and J. Chun, FEMS Microbiol. Lett., 2003, 223, 129-134.

18 G. Sabourin-Provost and P. C. Hallenbeck, Bioresour. Technol., 2009, 100, 3513-3517.

19 T. Ito, Y. Nakashimada, K. Senba, T. Matsui and N. Nishio, J. Biosci. Bioeng., 2005, 100, 260-265.

20 P. A. Marques, M. L. Bartolomeu, M. M. Tomé and L. Neves, Proceedings of Hypothesis VIII, Lisbon (Portugal), 2009.

21 T. A. Ngo, M. S. Kim and S. J. Sim, Int. J. Hydrogen Energy, 2011, 36, 5836-5842.

22 S. Sakai and T. Yagishita, Biotechnol. Bioeng., 2007, 98, 340348.

23 P. A. Selembo, J. M. Perez, W. A. Lloyd and B. E. Logan, Biotechnol. Bioeng., 2009, 104, 1098-1106.

24 S. Rittmann and C. Herwig, Microb. Cell Fact., 2012, 11, 115.

25 P. C. Hallenbeck and D. Ghosh, Trends Biotechnol., 2009, 27(5), 287-297.

26 S. E. Oh, S. Van Ginkel and B. E. Logan, Environ. Sci. Technol., 2003, 37, 5186-5190.

27 S. K. Khanal, W. H. Chen, L. Li and S. Sung, Int. J. Hydrogen Energy, 2004, 29, 1123-1131. 